\title{
Light-responsive block copolymers with a spiropyran located at the block
} junction

\author{
Edward A. Apebende ${ }^{1}$, Laurent Dubois ${ }^{2} \&$ Nico Bruns $^{1,3 *}$
}

${ }^{1}$ Adolphe Merkle Institute, University of Fribourg, Chemin des Verdiers 4, 1700

Fribourg, Switzerland

${ }^{2}$ Department of Chemistry, University of Basel, Mattenstrasse 24a, 4002 Basel, Switzerland

${ }^{3}$ Department of Pure and Applied Chemistry, University of Strathclyde, 295 Cathedral Street, Glasgow G1 1XL, UK

Submitted for publication to

The European Polymer Journal

e-mail addresses: Edward A. Apebende: edward.apebende@unifr.ch Laurent Dubois laurent.dubois@unibas.ch Nico Bruns*: $\quad$ nico.bruns@strath.ac.uk

* Author to whom correspondence should be addressed. 


\section{Abstract}

Block copolymers with a functional group between their blocks are relative little explored, even though this molecular architecture can reduce the aggregation of the functional groups, promote the phase separation in nanophase-separated materials, and have other interesting effects. Spiropyrans are wellknown for their ability to switch to their polar merocyanine form in response to light, force and other stimuli. The synthesis of stimuli-responsive AB-type block copolymers with spiropyran moieties located at the junction of the blocks is presented here. A homopolymer is synthesized from an indole-based atom transfer radical polymerization (ATRP) initiator, followed by its modification to a spiropyran endfunctionalized polymer. The spiropyran functionalized polymer is then used as a macro-initiator for the synthesis of a second polymer block by ring opening polymerization (ROP). Alternatively, spiropyran homopolymers are conjugated to other preformed polymers by esterification. The resulting block copolymers reversibly switch under UV and white light irradiation over multiple cycles, and a block copolymer reduced the tendency of the merocyanine to aggregate during switching. The stimuliresponsive block copolymer could be useful for a range of applications, e.g. for bioinspired polymersome nanoreactors, or in membranes with switchable permeability.

\section{Keywords}

Spiropyran, block copolymer, stimuli-responsive material, atom transfer radical polymerization, ring opening polymerization, polymer-polymer conjugation

\section{Introduction}

There is currently a huge interest in stimuli responsive polymers i.e. materials that change their properties in response to certain external stimuli such as light, temperature, chemicals, magnetic fields, electric fields, and mechanical force.[1-4] One reason for this interest is that they mimic the ability of living materials to adapt and respond to their environment.[4-6] Moreover, such polymers are investigated for a multitude of application, including smart textiles, sensors, actuators, and controlled release systems.[4, $5,7,8]$ For many applications, block copolymers are desirable. Block copolymers self-assemble in solution into various nanostructures such as micelles and vesicles. In the bulk they form nanophaseseparated morphologies such as gyroid, lamellar or hexagonal phases.[9] The former can be used in drug delivery and nanoreactors applications,[9-12] while structured bulk materials find applications, e.g. as scaffolds for energy materials.[9] Functional groups in block copolymers can either be distributed along the side chains of the blocks, incorporated into the backbone of the chains, or they can be situated at the junction of blocks. The first two approaches are most commonly followed because they result in a high number of functional groups per polymer chain. Nevertheless, polymer architectures in which one functional group is located between two blocks have their own advantages.[13-15] The prime example are light-responsive or reduction-sensitive groups that cleave in response to an external stimulus, thereby leading to the destruction of the block copolymer and its self-assembled structures.[13-18] Noncleavable functional groups that have been incorporated between blocks include attachment points that allow to prepare dense mixed polymer brushes on surfaces,[19] and micelles with mixed hydrophilic corona.[20] When a fluorophore is located in between blocks, it will be dispersed at the interface of hydrophilic and hydrophobic domains in self-assembled nanostructures, thereby reducing aggregationinduced quenching.[21, 22] This can, e.g., enhance the fluorophore's effect in light-responsive drug delivery systems.[22] Moreover, an ionic or $\mathrm{H}$-bonding residue at the junction of blocks can greatly influence the self-assembly behavior of the block copolymers, e.g. by promoting the phase separation between blocks, and by shifting the order-to-disorder transition in bulk systems to higher 
temperatures.[23-27] However, stimuli-responsive switchability of a functional moiety between blocks has not been explored in these applications.

Spiropyrans are one of the most famous examples of stimuli-responsive motifs. They are responsive to several environmental factors such as light and mechanical force.[28-32] When stimulated, spiropyrans undergo a reversible $6-\pi$ electrolytic ring opening reaction to the merocyanine form accompanied by a change in color.[33] Initially discovered in the early 1900s, their ability to respond to stimuli was first reported in 1954 by Hirshberg and Fischer.[34] The functionalization of polymers with spiropyrans has been demonstrated to afford polymeric materials that show dynamic and reversible switching of properties such as electrical conductivity,[35-37] wetting behavior,[38-40] metal-ion complexation,[4143] cell adhesion,[44] and membrane permeability.[38, 45, 46] The functionalization of polymers with spiropyrans is usually achieved by the polymerization of spiropyran functionalized monomers,[46-51] or the functionalization of pre-made polymers with spiropyran derivatives.[46, 52-54] Other approaches involve initiating polymerization from spiropyran initiators for ring opening polymerization (ROP), [30, 55] free radical polymerization,[56] and atom transfer radical polymerization (ATRP), [28, 29, 57, 58] as well as the synthesis of main chain spiropyran polymers by Suzuki polycondensation.[59] These approaches afford polymers with spiropyran units as side groups, at the chain ends, or located in the backbone of one block. In contrast, block copolymers that feature the spiropyran at the junction of two blocks have not been reported. This placement of the responsive group could be highly beneficial, e.g. to reduce the tendency of merocyanine to aggregate, an effect which can slow down the switching kinetics.[33] Moreover, the light-induced polarity changes between the uncharged spiropyran and the zwitterionic merocyanine could be exploited to shift the order-disorder transition temperature in phaseseparated materials. The mechanochemistry of spiropyrans might also be influenced in unprecedented ways by locating the mechanophore in between blocks.

Herein, we present synthesis routes to AB-type block copolymers that feature a single spiropyran at the block junction (Scheme 1), and investigate their light-switching behavior. We chose to prepare an ATRP initiator linked to an indoline derivative, which was converted into a spiropyran after the polymerization, yielding spiropyran-terminated polymer chains. They were then used as macro-initiators for ROP, or they were conjugated to other preformed polymers by esterification. The spiropyran of the homo and the block copolymers could be reversibly switched to their merocyanine form in bulk materials. While the merocyanine of certain homopolymers aggregated, aggregation was suppressed in some of the block copolymers. 


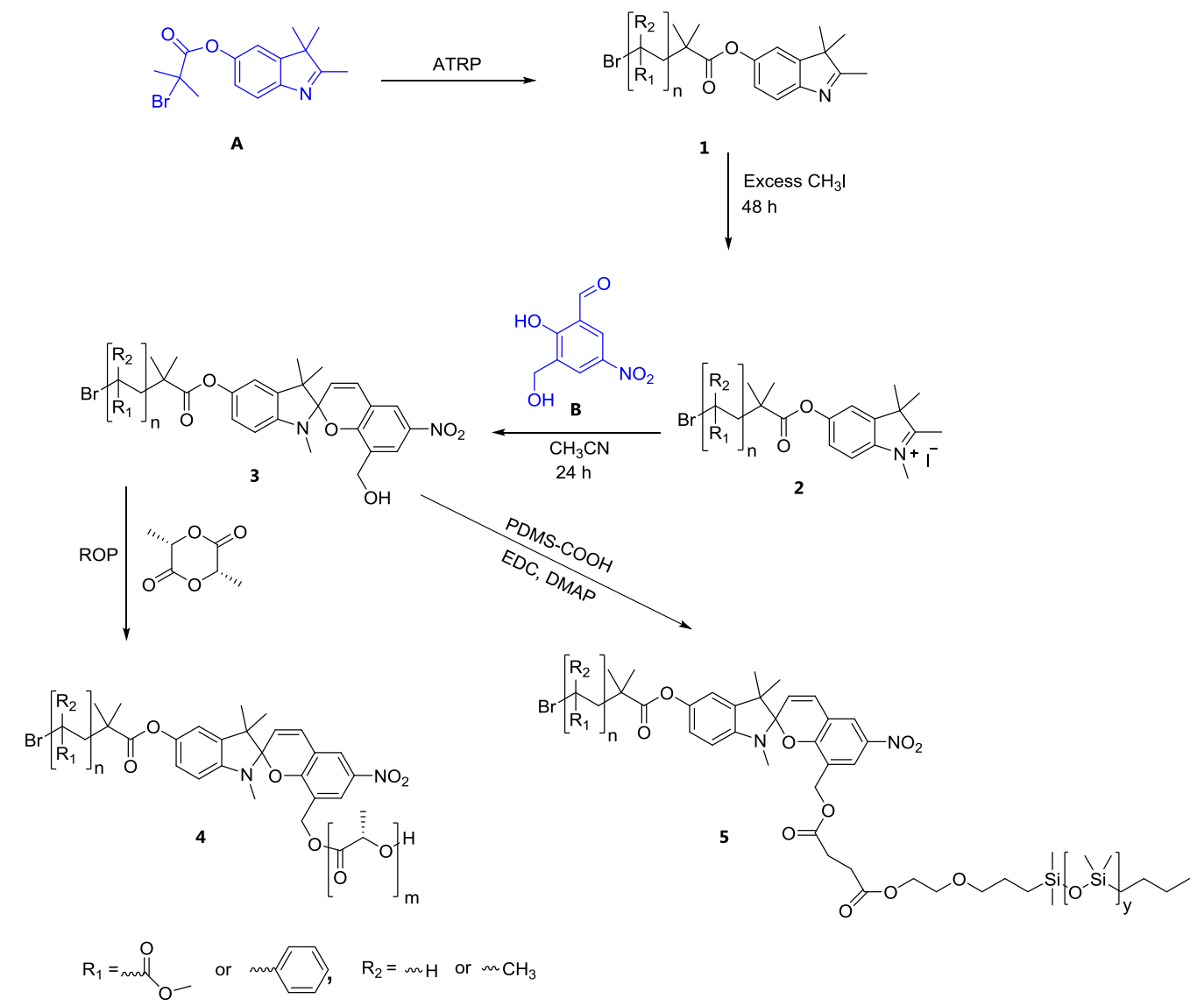

Scheme 1 : Synthesis routes to AB type block copolymers with a spiropyran moiety located at the junction of both blocks.

\section{Experimental}

\subsection{Materials}

$\alpha$-Bromoisobutyryl bromide, (4-methoxy)-phenyl hydrazine hydrochloride, triethylamine, methyl isopropyl ketone, iodomethane, 4-(dimethylamino) pyridine (DMAP), N,N,N',N",N"pentamethyldiethylenetriamine (PMDETA), copper (II) bromide (CuBr), piperidine, sodium hydroxide, hydrogen bromide, $\mathrm{N}^{\prime}$-ethylcarbodiimide hydrochloride (EDC), L-lactide, 1,8-diazabicyclo[5.4.0]undec7-ene (DBU), 3,5-bis(trifluoromethyl)phenyl isothiocyanate , cyclohexylamine, acetonitrile, tetrahydrofuran (THF), chloroform, dichloromethane (DCM), dimethyl sulfoxide (DMSO), methyl acrylate, methyl methacrylate and styrene were obtained from Sigma Aldrich. Poly(dimethylsiloxane)- $\omega$-carboxy acid terminated, (number average molecular weight $\mathrm{M}_{\mathrm{n}}=10000 \mathrm{~g} \mathrm{~mol}^{-1}$, dispersity $Đ=1.09$, Product ID: P8645-DMSCOOH) was obtained from Polymer Source while 3-chloromethyl-5-nitrosalicylaldehyde was obtained from TCI-Europe.

\subsection{Synthesis of Small Molecule Precursors}

2.2.1. Synthesis of 5-methoxy-2,3,3-trimethyl-3H indole, 2,3,3-trimethyl-3H-indol-5-ol, 2-hydroxy-3(hydroxymethyl)-5-nitrobenzaldehyde (B) and bis(3,5-trifluoromethyl)phenyl cyclohexylthiourea. These compounds were prepared according to previously reported procedures.[28-30, 60]

\subsubsection{Synthesis of 2,3,3-trimethyl-3H-indol-5-yl 2-bromo-2-methylpropanoate, $\boldsymbol{A}$.}

A $100 \mathrm{~mL}$ round bottom flask was equipped with a magnetic stirrer and charged with 2,3,3-trimethyl$3 \mathrm{H}$-indol-5-ol $(0.90 \mathrm{~g}, 5.14 \mathrm{mmol})$ and triethylamine $(5.4 \mathrm{mmol}, 0.75 \mathrm{~mL})$ dissolved in anhydrous THF (40 
$\mathrm{mL})$. The mixture was cooled to $0^{\circ} \mathrm{C}$ in an ice bath following which $\alpha$-bromoisobutyryl bromide $(0.67 \mathrm{~mL}$, $5.4 \mathrm{mmol}$ ) was added dropwise. The reaction mixture was allowed to stir for 3 hours at $0^{\circ} \mathrm{C}$ and then at room temperature for $16 \mathrm{~h}$. The salt was filtered off, and the filtrate was concentrated with a rotary evaporator to give a brown viscous liquid which was further purified by column chromatography eluting with hexane/ethyl acetate ( $\mathrm{v}: \mathrm{v} 1: 1)$. The product was obtained as a brown viscous oil $(\mathrm{Rf}=0.43)$. Yield= $78 \%$.

${ }^{1} \mathrm{H}$ NMR $(400 \mathrm{MHz}$, Chloroform-d) $\delta 7.48(\mathrm{~d}, J=8.1 \mathrm{~Hz}, 1 \mathrm{H}), 7.12-6.81(\mathrm{~m}, 2 \mathrm{H}), 2.22(\mathrm{~s}, 3 \mathrm{H}), 2.00(\mathrm{~s}, 6 \mathrm{H})$, $1.24(\mathrm{~s}, 6 \mathrm{H})$.

${ }^{13} \mathrm{C}$ NMR $(101 \mathrm{MHz}$, Chloroform-d) $\delta 188.92,170.46,150.94,148.63,146.81,120.22,114.64,55.43,54.15$, $31.07,30.66,22.97,15.27$.

\subsection{Polymer Synthesis and Functionalization}

\subsubsection{Representative Procedure for the Synthesis of Indole Functionalized Polymers by ATRP}

A $50 \mathrm{~mL}$ Schlenk tube was equipped with a magnetic stir bar and charged with a solution of compound 4 ( $0.22 \mathrm{~g}, 0.67 \mathrm{mmol}, 1$ equiv.) in $0.5 \mathrm{~mL}$ DMSO. CuBr $(0.19 \mathrm{~g}, 1.33 \mathrm{mmol}, 2$ equiv.) and methyl acrylate (21.05 mL, $232.3 \mathrm{mmol}, 346$ equiv.) were added to the Schlenk tube. The tube was sealed with a rubber septum, connected to a vacuum line and subjected to three freeze-pump-thaw cycles to remove oxygen. Afterwards, the flask was filled with argon and the ligand PMDETA $(0.42 \mathrm{~mL}, 2.0 \mathrm{mmol}, 3$ equiv.) was added. The tube was placed in an oil bath at $60{ }^{\circ} \mathrm{C}$. After $180 \mathrm{~min}$ the reaction was stopped by opening it to air. The polymer was dissolved in THF and passed through a neutral alumina plug to remove copper. The polymer was finally purified by precipitating into cold methanol. The methanol was decanted and the polymer was collected and dried in a vacuum oven at $80^{\circ} \mathrm{C}$ for $24 \mathrm{~h}$. Yield $=89 \%$.

\subsubsection{Representative Procedure for the Synthesis of Spiropyran End Functionalized Polymers.}

Indolenine functionalized poly(methyl acrylate), 1 ( $2 \mathrm{~g}, 0.066 \mathrm{mmol}, 1$ equiv.) was placed in a round bottom flask equipped with a magnetic stir bar. It was dissolved in an excess of iodomethane $(20 \mathrm{~mL}$, $321.26 \mathrm{mmol}$ ). The flask was connected to a reflux condenser and the mixture was refluxed at $42{ }^{\circ} \mathrm{C}$ for $48 \mathrm{~h}$. Afterwards, the excess iodomethane was distilled off and the macro indolenine salt, 2 was used without further purification. Compound 2 was dissolved in a toluene/acetonitrile 4:1 (v:v) mixture. Compound B ( $0.039 \mathrm{~g}, 0.198 \mathrm{mmol}, 3$ equiv.) and piperidine $(0.014 \mathrm{~mL}, 0.132 \mathrm{mmol}, 2$ equiv.) were added to the solution. The mixture was refluxed at $100^{\circ} \mathrm{C}$ for $24 \mathrm{~h}$. Then it was stopped, cooled and the solvent removed under vacuum. The reaction mixture was then re-dissolved in minimal THF and it was precipitated into a large excess of cold methanol. The precipitation was repeated twice before the polymer was collected and dried in a vacuum oven at $80^{\circ} \mathrm{C}$. Yield $=92 \%$.

\subsubsection{Representative Procedure for the Synthesis of Spiropyran Functionalized AB Block Copolymers by} Polymer Chain Extension.

Polymerization of L-lactide from spiropyran functionalized PMA macro initiator was performed in a glovebox. Spiropyran end functionalized poly(methyl acrylate), 3 (1 g, $0.033 \mathrm{mmol}$ ) was placed in in a round bottom flask equipped with a magnetic stir bar. The monomer, L-lactide $(1 \mathrm{~g}, 6.9 \mathrm{mmol})$ and cocatalyst, bis(3,5-trifluoromethyl)phenyl cyclohexylthiourea, $(0.012 \mathrm{~g}, 0.04 \mathrm{mmol}, 1.2$ equiv.) were added and they were dissolved in anhydrous chloroform $(30 \mathrm{~mL})$. The catalyst DBU $(0.01 \mathrm{~mL}, 0.067 \mathrm{mmol}, 2$ equiv.) was added and the reaction mixture was left stirring at room temperature for $3 \mathrm{~h}$. The reaction was then stopped by opening the reaction mixture to air. The mixture was concentrated in vacuo and 
then precipitated into cold methanol. The polymer was collected and dried in a vacuum oven at $80^{\circ} \mathrm{C}$ for $24 \mathrm{~h}$. Yield $=78 \%$.

2.3.4. Representative Procedure for the Synthesis of Spiropyran Functionalized AB Block Copolymers by Polymer-Polymer Conjugation.

Spiropyran functionalized AB block copolymer; PMMA-SP-PDMS was synthesized by EDC-activated esterification of spiropyran end functionalized homopolymers, PMMA-SP to carboxy-functionalized polydimethlysiloxane, PDMS-COOH. PMMA-SP ( $1 \mathrm{~g}, 0.033 \mathrm{mmol}, 1$ equiv.) and PDMS-COOH $(0.5 \mathrm{~g}, 0.05$ mmol, 1.5 equiv.) were placed in a dry round bottom flask equipped with a magnetic stir bar. DCM (40 $\mathrm{mL}$ ) was added to dissolve them. Then, the flask was sealed with a rubber stopper, flushed with argon, cooled in an ice bath to $0{ }^{\circ} \mathrm{C}$ and left to stir for $15 \mathrm{~min}$. Afterwards, DMAP $(0.002 \mathrm{~g}, 0.016 \mathrm{mmol}, 0.5$ equiv.) and EDC ( $0.013 \mathrm{~g}, 0.066 \mathrm{mmol}, 2$ equiv.) were dissolved in DCM $(5 \mathrm{~mL})$ and added dropwise with a syringe. The reaction mixture was then left to stir at room temperature for $24 \mathrm{~h}$. The reaction mixture was washed with water ( 3 times), and then concentrated in vacuo before precipitating the polymer into cold hexane. The polymer was further washed with cold hexane and then dried at $80^{\circ} \mathrm{C}$ in the oven for 24 hrs. Yield $=93 \%$.

\section{Methods}

Nuclear Magnetic Resonance Spectroscopy (NMR). NMR spectra were recorded at room temperature on a Bruker Advance III $400 \mathrm{MHz}$ spectrometer using deuterated solvents. Chemical shifts $(\delta)$ are reported in ppm, and the chemical shifts are calibrated to the solvent residual peaks.

UV-visible Spectroscopy (UV-vis). UV-vis spectra were recorded using an Analytik Jena Specord 50 PLUS spectrometer from $190 \mathrm{~nm}$ to $700 \mathrm{~nm}$, using quartz cuvettes with a path length of $10 \mathrm{~mm}$ and quartz slides positioned perpendicular to the beam.

Gel Permeation Chromatography (GPC). GPC measurements were performed on an Agilent 1200 series HPLC system equipped with an Agilent PLgel mixed guard column (particle size $=5 \mu \mathrm{m}$ ) and two Agilent PLgel mixed-D columns (ID $=7.5 \mathrm{~mm}, \mathrm{~L}=300 \mathrm{~mm}$, particle size $=5 \mu \mathrm{m}$ ). Signals were recorded by an Optilab REX interferometric refractometer. Samples were run using THF as the eluent at $30{ }^{\circ} \mathrm{C}$ and a flow rate of $1.0 \mathrm{~mL} \mathrm{~min}{ }^{-1}$. Data analyses were done on Astra software (Wyatt Technology Corp.) and molecular weights were determined based on narrow-molecular weight polystyrene calibration (from 2340 to $364000 \mathrm{~g} \mathrm{~mol}^{-1}$.

Differential Scanning Calorimetry (DSC). DSC measurements were performed under $\mathrm{N}_{2}$ using a MettlerToledo STAR system operating at a heating/cooling rate of $10^{\circ} \mathrm{C} \mathrm{min}^{-1}$ in the range of -80 to $250{ }^{\circ} \mathrm{C}$ and the second heating cycle is shown.

Photography. Images were acquired with a Nikon D7100 digital camera equipped with an AF-S DX ZoomNIKKOR 18-135mm lens (f/3.5-5.6G IF-ED). The depicted objects were cropped with Microsoft PowerPoint to create a white background.

\subsection{Results and discussion}

\subsection{Synthesis of spiropyran functionalized homopolymers}

Typically, spiropyrans are synthesized by reacting $o$-hydroxy benzaldehydes with idolenium salts in the presence of piperidine.[61] They may be linked to polymers by utilizing them as initiators or quenchers, or by coupling them to functional groups on the polymer chain.[28,61,62] Our approach to make spiropyran end-functionalized homopolymers is to first synthesize a macro-indolenium salt and then 
treat it with a suitable o-hydroxy benzaldehyde. This allows to synthesize and characterize polymers without the notoriously tedious purification of small molecule spiropyrans. For this purpose, 2,3,3trimethyl-3H-indol-5-yl 2-bromo-methylpropanoate, A was synthesized by the esterification of 2,3,3trimethyl-3H-indol-5-ol with $\alpha$-bromoisobutyryl bromide. It was utilized as an initiator for the ATRP of methyl acrylate (Scheme 1). The resulting indole functionalized poly(methyl acrylate), $\mathbf{1}$ was converted to the corresponding indolenium salt, $\mathbf{2}$ by refluxing with iodomethane. This was then treated with 3hydroxymethyl-5-nitrobenzaldehyde, $\mathbf{B}$ in the presence of piperidine to yield spiropyran functionalized poly(methyl acrylate). The need for extensive purification that is usually associated with the synthesis of spiropyrans is eliminated here as the product can easily be purified by precipitation in appropriate solvents, such as methanol. UV-vis spectra of indole functionalized poly(methyl acrylate), $\mathbf{1}$ and spiropyran functionalized poly(methyl acrylate), 3 (Fig. 1) show two bands. The first band at $\sim 272-296$ $\mathrm{nm}$ comes from the $\pi-\pi^{*}$ transitions within the indole part of spiropyrans. It can be seen in both spectra. The second band at $\sim 323-351 \mathrm{~nm}$ corresponds to the chromene part of spiropyrans and is typical of spiropyrans in their closed form. It appears only after the spiropyran has been formed. This indicates that the polymer was successfully functionalized with spiropyran end groups.

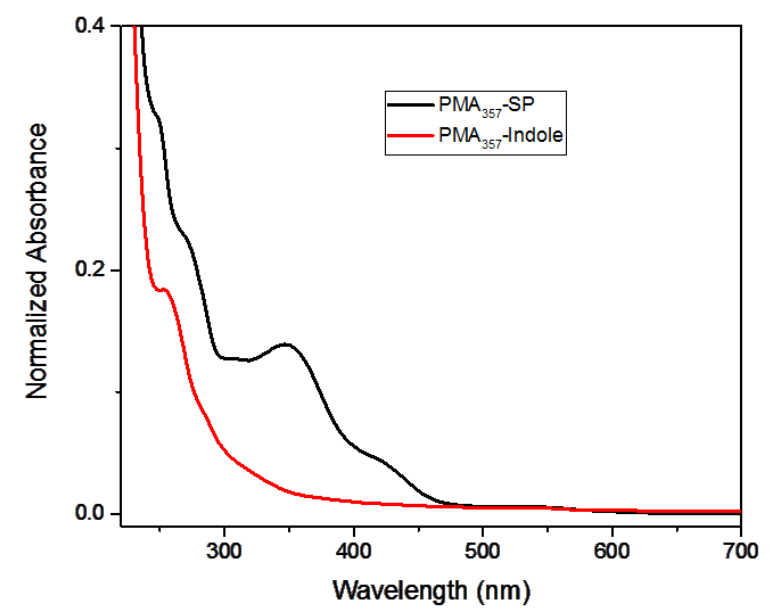

Fig. 1: UV-vis spectra of indole functionalized poly(methyl acrylate) and spiropyran functionalized poly(methyl acrylate).

Spiropyran functionalized poly(methyl acrylate) with molecular weight below $10000 \mathrm{~g} \mathrm{~mol}^{-1}$ was specifically synthesized to allow for characterization by NMR spectroscopy. The ${ }^{1} \mathrm{H}$ NMR spectrum of spiropyran functionalized poly(methyl acrylate), $\mathrm{PMA}_{38}$-SP shows peaks at $8.11,7.89,6.43$, and $4.41 \mathrm{ppm}$ that are absent in the spectrum of indole functionalized poly(methyl acrylate) (Fig. 2(a)). These peaks can be assigned to the formed spiropyran functional group. The indole functionalized poly(methyl acrylate)'s aromatic signals have also shifted from 7.1 and $7.5 \mathrm{ppm}$ to 6.9 and $6.8 \mathrm{ppm}$. The molecular weights were calculated by comparing the integral of the peaks at $7.5 \mathrm{ppm}$ in the case of indole functionalized poly(methyl acrylate) and $7.89 \mathrm{ppm}$ for spiropyran functionalized poly (methyl acrylate) to the polymer's methylene peak at $2.25 \mathrm{ppm}$ and are reported in Table 1. To estimate the degree of functionalization of the polymer with the spiropyran motifs, the peak from the spiropyran group at 8.11 was compared to the methylene peak from the other end of the polymer chain seen at 2.49 ppm (Fig. 2(b)). 


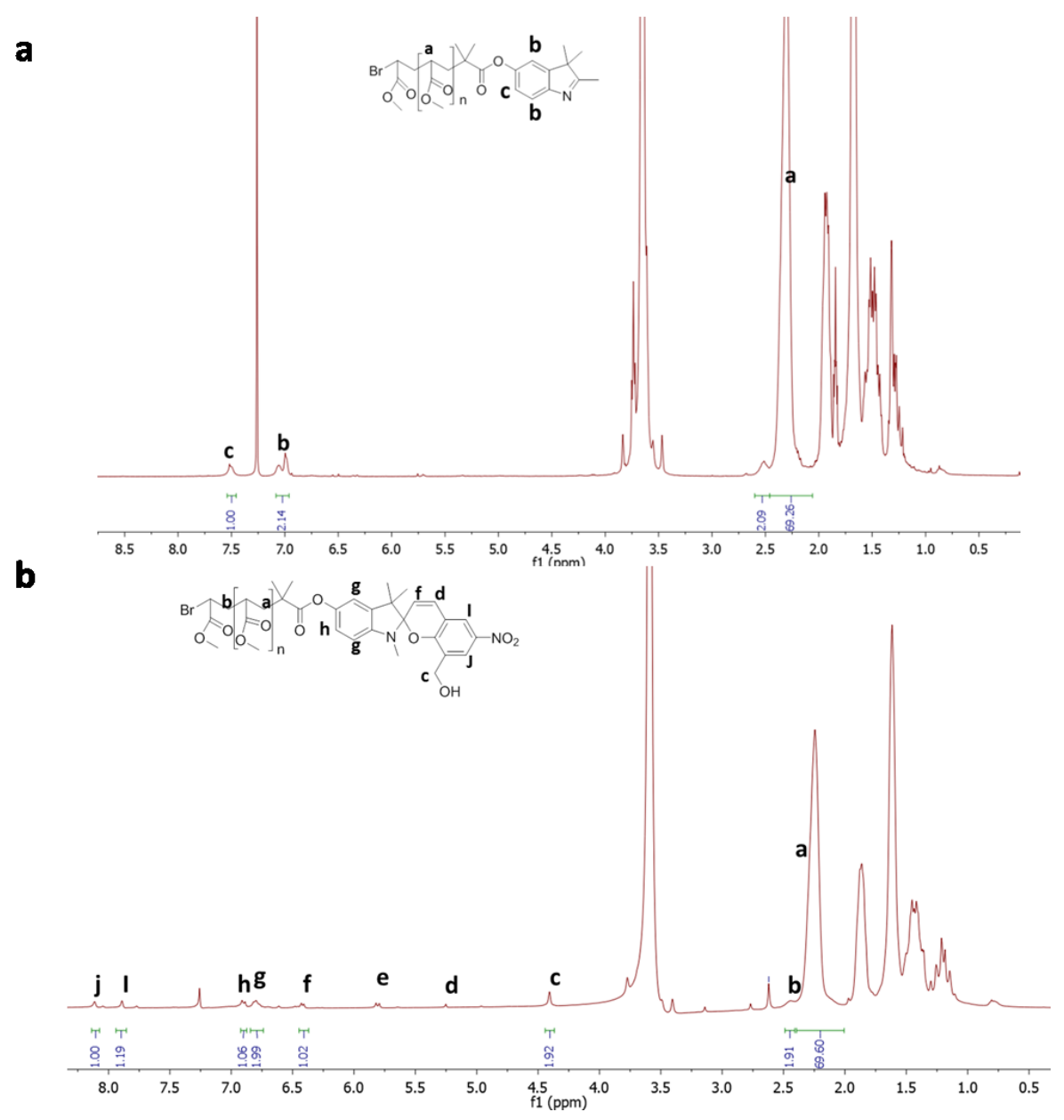

Fig. 2: ${ }^{1} \mathrm{H}$ NMR spectra of (a) indole functionalized poly(methyl acrylate) $\left(\mathrm{PMA}_{38}\right.$-indole) and (b) spiropyran functionalized poly(methyl acrylate) (PMA $\left.\mathrm{PM}_{38} \mathrm{SP}\right)$.

This way, it could be shown that a functionalization of $96 \%$ was achieved. To demonstrate the simplicity of the method, other spiropyran functionalized polymers were also synthesized following the same procedure. The synthesized homopolymers and their molecular weights are listed in Table 1. Although ATRP typically yields polymers with low dispersities, some of the polymers obtained here had relatively broad molecular weight distributions. Most likely, this is due to the fact the polymerizations were conducted in the bulk where the increasing viscosities of the reaction mixtures during the polymerization lead to reduced mobility of reagents and consequently hindered uniform growth of the polymer chains. Nevertheless, molecular weights are within target range and the dispersities do not affect the further modification of the polymers with spiropyran motifs or their use for the synthesis of block copolymers.

Table 1: Molecular weights of spiropyran functionalized homopolymers.

\begin{tabular}{ccccc}
\hline Entry & Polymer & $\mathrm{M}_{\mathrm{n}}\left(\mathrm{g} \mathrm{mol}^{-1}\right) \mathrm{GPC}$ & $\mathrm{M}_{\mathrm{n}}\left(\mathrm{g} \mathrm{mol}^{-1}\right) \mathrm{NMR}$ & Dispersity \\
\hline 1 & $\mathrm{PMA}_{38}-\mathrm{SP}$ & 3300 & 3000 & 1.32 \\
2 & $\mathrm{PMA}_{357}-\mathrm{SP}$ & 30700 & $-^{\mathrm{a}}$ & 1.60 \\
3 & $\mathrm{PS}_{68}-\mathrm{SP}$ & 7100 & 6700 & 1.27 \\
4 & $\mathrm{PS}_{342}-\mathrm{SP}$ & 35600 & $-^{\mathrm{a}}$ & 2.02 \\
5 & $\mathrm{PMMA}_{316}-\mathrm{SP}$ & 31600 & $-^{\mathrm{a}}$ & 1.65 \\
\hline
\end{tabular}

aMolecular weight estimation by NMR was not carried out for polymers above $10000 \mathrm{~g} \mathrm{~mol}^{-1}$ because the signals of the endgroups could not be accurately integrated. 
When irradiated with UV light, the synthesized homopolymers all showed visual color changes to slightly different shades of purple as can be seen in Fig. 3(a). To confirm that the observed color changes were indeed manifestations of the switching of the spiropyrans into the merocyanine form, the polymers were solution cast on quartz slides to create a film of the polymers upon evaporation of the solvents. The polymer films were then subjected to UV light irradiation (354 nm wavelength), and their absorption spectra were recorded at specific intervals. For all three polymers studied, $\mathrm{PMA}_{357}-\mathrm{SP}, \mathrm{PS}_{342}-\mathrm{SP}$, and $\mathrm{PMMA}_{316}$-SP, an increase in absorbance between 550 and $600 \mathrm{~nm}$ was observed (Fig. 3(c-e)). PMA $\mathrm{P}_{357^{-}}$ $\mathrm{SP}$ developed a single absorption band with a maximum at $566 \mathrm{~nm}$. It corresponds to non-aggregated merocyanine.[33] The other two polymers showed more complex spectra. In the case of $\mathrm{PS}_{342}-\mathrm{SP}$, two peaks at 505 and $626 \mathrm{~nm}$ developed into a broad adsorption band that is dominated by the absorption around $595 \mathrm{~nm}$. For $\mathrm{PMMA}_{316}-\mathrm{SP}$, the main peak at $564 \mathrm{~nm}$ was accompanied by shoulders at approx. $525 \mathrm{~nm}$ and at $585 \mathrm{~nm}$. The maximum absorbance in the spectra differs between the samples because the films had different thicknesses. It is well-established in literature that spiropyrans, when switching into their merocyanine form, can stack in parallel ( $\mathrm{H}$-aggregates) and head-to-tail (J aggregates). $[33,63]$ The $\mathrm{H}$-aggregates have an absorption that is blue-shifted to lower wavelengths (depending on the system e.g. around $500 \mathrm{~nm}$ [64] or 520-550 nm[65]), while the J aggregates absorb at higher wavelengths than the free merocyanine (e.g. around $610 \mathrm{~nm}[64]$ or between $600-640 \mathrm{~nm}[65]$ ). Occasionally, both types of crystals are observed at the same time.[64,65] Moreover, these stacks can also form in the dark, thereby causing the spiropyran to switch. The process is called zipper crystallization.[66] Thus, the spectra of the spiropyran-functionalized homopolymers reveal that $\mathrm{H}$ - and J-aggregates formed in the solid state. A plot of the change in absorbance with time for $\mathrm{PMA}_{357}$-SP (Fig. 3(b)) shows that the response saturates at approx. 35 min of UV irradiation. Similar curves for PMMA PM16 $_{3}$ SP and PS $_{342}-\mathrm{SP}$ are provided in Fig. S3.1 and Fig. S3.2 in the supporting information. In the absence of UV light, the films revert to their initial color over several hours. 
(a)

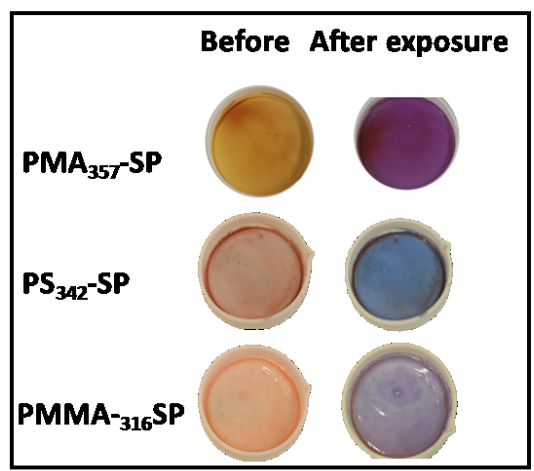

(b)

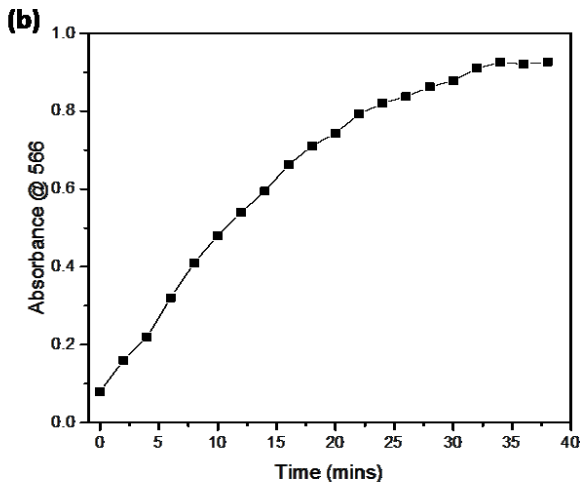

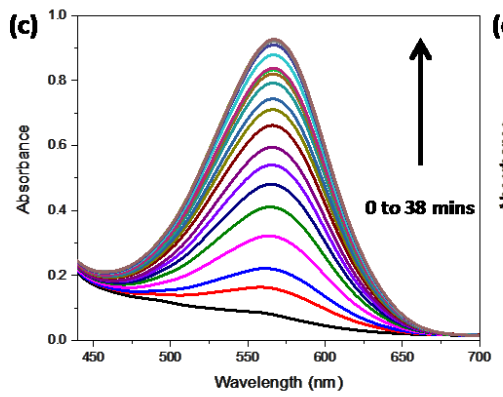
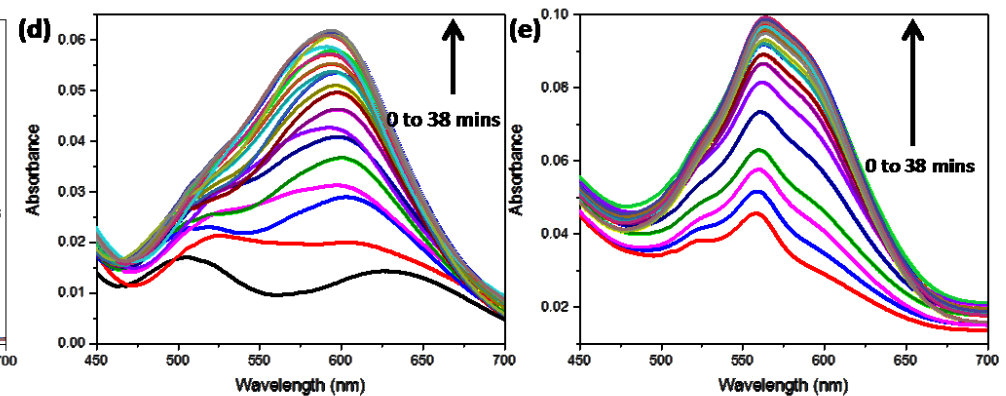

Fig. 3: UV-light response of spiropyran functionalized homopolymers. (a) Photos of homopolymer films showing the color change of the materials upon irradiation with UV light for $20 \mathrm{~min}$. (b) Change of absorbance with time for PMA $\mathrm{A}_{357}-\mathrm{SP}$ upon irradiation with UV-light. (c) Vis-spectra of $\mathrm{PMA}_{357}$-SP upon irradiation with UV-light. (d) Vis-spectra of $\mathrm{PS}_{342}-\mathrm{SP}$ upon irradiation with UV-light. (e) Vis-spectra of PMMA ${ }_{316}$-SP upon irradiation with UV-light. Spectra were recorded every 2 min.

\section{Synthesis of block copolymers with a spiropyran at the junction of the blocks}

The spiropyran end functionalized homopolymers had a terminal hydroxyl group, which was used for the synthesis of $A B$ block copolymers by the chain extension approach through ROP, and by polymerpolymer conjugation through EDC coupling. The block copolymers so obtained and their GPC data are shown in Table 2.

Table 2: GPC data of block copolymers with a spiropyran at the junction of blocks that were prepared by chain extension from spiropyran functionalized homopolymers and by polymer-polymer coupling.

\begin{tabular}{ccccc}
\hline Entry & Polymer & Target $\mathrm{M}_{\mathrm{n}}\left(\mathrm{g} \mathrm{mol}^{-1}\right)$ & Actual $\mathrm{M}_{\mathrm{n}}\left(\mathrm{g} \mathrm{mol}^{-1}\right)$ & Dispersity \\
\hline 1 & $\mathrm{PMA}_{357}-\mathrm{SP}-\mathrm{PLLA}$ & 50000 & 35800 & 1.72 \\
2 & $\mathrm{PMA}_{357}-$ SP-PDMS $_{135}$ & 40700 & 39800 & 1.70 \\
3 & $\mathrm{PS}_{342}-$ SP-PDMS $_{135}$ & 45600 & 43000 & 1.81 \\
4 & PMMA $_{316}-$ SP-PDMS $_{135}$ & 41600 & 41400 & 1.59 \\
\hline
\end{tabular}

The main requirement for block copolymer synthesis by chain extension is the availability of a polymer with a suitable initiating group. In other words, the first block should be end-functionalized with the needed initiating group that the second block can be grown therefrom. The terminal secondary hydroxyl groups on the synthesized spiropyran end-functionalized homopolymers can be activated by hydrogen bond acceptor organo-catalysts such as 1,8-diazabicyclo[5.4.0]undec-7-ene (DBU) to generate the anionic species necessary for initiation and propagation in anionic ring opening polymerizations. Therefore, $\mathrm{PMA}_{357}$-SP was employed as a macro-initiator for the organo-catalytic ring opening polymerization of L-lactide following well established protocols. The NMR spectrum shows new polymer peaks which can be assigned to the lactide block (Fig. S2.13, supporting information). Fig. 4 shows a 
shift to lower retention times in the gel permeation chromatography (GPC) trace going from $\mathrm{PMA}_{357}-\mathrm{SP}$ to $\mathrm{PMA}_{357}-\mathrm{SP}_{-}$PLLA 81 indicating an increase in molecular weight of the polymer as the second block is formed. The molecular weight of the block copolymer is smaller than targeted, as the ROP most likely did not reach full conversion. Taken together, this data shows that the ATRP-derived homopolymer was converted into a block copolymer by chain extension through ROP.

Block copolymer synthesis by polymer-polymer conjugation requires two polymers that are end functionalized with complementary functional groups. This approach is starting to become main stream because of well-established conjugation chemistries and the emergence of new "click" chemistries. It has been employed for the synthesis of various graft and block copolymers.[67] The hydroxy groups on the synthesized spiropyran end-functionalized homopolymers are complementary to carboxylic acid groups and are suitable for block copolymer synthesis by esterification with carboxy-functionalized polymers. Spiropyran end-functionalized poly(methyl acrylate) $\left(\mathrm{PMA}_{357}-\mathrm{SP}\right)$, polystyrene, $\left(\mathrm{PS}_{342}-\mathrm{SP}\right)$ and poly(methyl methacrylate) (PMMA $\left.{ }_{316}-\mathrm{SP}\right)$ were, therefore, coupled to carboxy-functionalized polydimethylsiloxane $\left(\mathrm{M}_{\mathrm{n}}=10000 \mathrm{~g} \mathrm{~mol}^{-1}\right)$ by conventional EDC coupling protocols. Others have previous shown that this chemistry is efficient for the synthesis of block copolymers.[68] An excess of the PDMS-COOH was used to ensure the complete functionalization of all spiropyran functionalized homopolymers. Unreacted PDMS- $\mathrm{COOH}$ was removed after the reaction by precipitating the block copolymer into cold hexane. A shift to shorter retention times in the GPC traces between the homopolymers and the block copolymer indicates that the polymers were indeed attached to each other (Fig. 4). Also, the NMR spectra show the appearance of new polymer peaks which can be assigned to the PDMS block (Fig. S2.14 - S2.16, supporting information). Thus, block copolymers were successfully synthesized. Current approaches to synthesize spiropyran functionalized block copolymers with the spiropyran motif located within the polymer backbone (but not at the block junction) are limited to polymers made by ATRP or ROP. The polymer-polymer coupling approach presented herein allows the incorporation of many kinds of polymers, and this possibility is only limited by the availability of carboxyfunctional groups on the desired polymer.

The block copolymers were further characterized by differential scanning calorimetry (DSC) (Fig. 5). For $\mathrm{PMA}_{357}$-SP-PLLA 81 , one glass transition point $\left(\mathrm{T}_{\mathrm{g}}\right)$ at $15^{\circ} \mathrm{C}$ and no crystallization peak of PLLA is observed. It has been previously reported that a polyacrylate or polymethacrylate block can suppress the crystallization of PLLA in block copolymers.[69] Our results indicate that this is also the case for $\mathrm{PMA}_{357^{-}}$ SP-PLLA ${ }_{81}$. The presence of only one $T_{g}$ that is below the one of pure PLLA $\left(61.7^{\circ} \mathrm{C}\right)$ indicates that the blocks do not fully phase separate, even though they are immiscible.[70] The same observations were made previously.[69] Thus, our results are consistent with literature.

In the measured temperature range, the PDMS-based block copolymers each have a $\mathrm{T}_{\mathrm{g}}\left(\mathrm{PMA}_{357} \mathrm{SP}-\right.$ $\left.\mathrm{PDMS}_{135}: 18^{\circ} \mathrm{C}, \mathrm{PS}_{342}-\mathrm{SP}-\mathrm{PDMS}_{135}=105^{\circ} \mathrm{C}, \mathrm{PMMA}_{316}-\mathrm{SP}-\mathrm{PDMS}_{135}=100^{\circ} \mathrm{C}\right)$ and no further thermal transitions. They are close to the literature-reported $\mathrm{T}_{\mathrm{g}} \mathrm{S}$ for PMA $\left(10^{\circ} \mathrm{C}\right),[71] \mathrm{PS}\left(100{ }^{\circ} \mathrm{C}\right),[72]$ and PMMA $\left(114^{\circ} \mathrm{C}\right)$. [73] It should be noted that the $\mathrm{T}_{g}$ of PDMS is lower than the onset of the 
measurements and can therefore not be observed. These results allow to conclude that the PDMSbased block polymers are amorphous, microphase-separated materials.
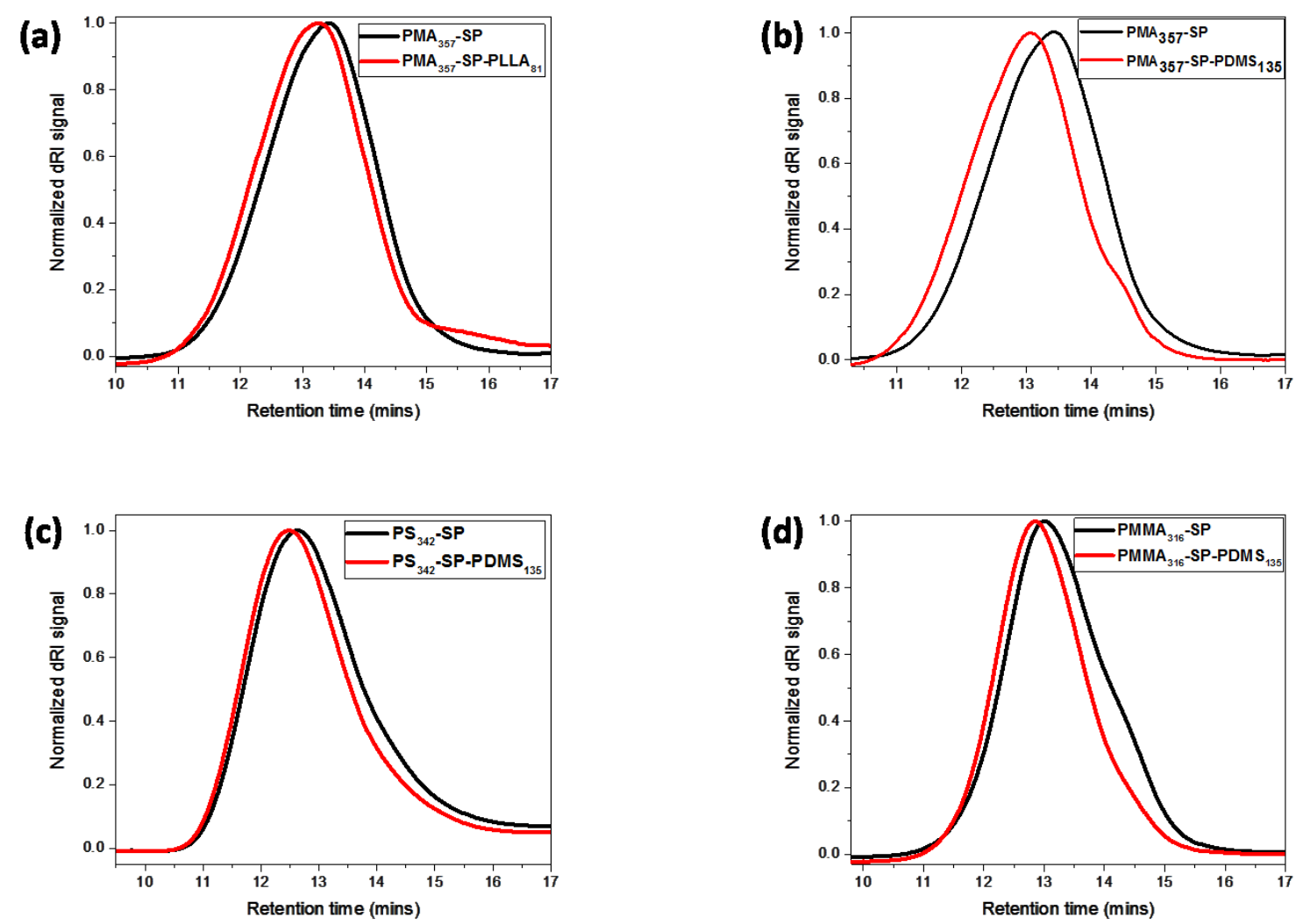

Fig. 4: GPC traces of spiropyran functionalized homopolymers and $A B$ block copolymers. (a) PMA $A_{357}-S P$ to PMA-357 SP-PLLA by polymer chain extension. (b) $\mathrm{PMA}_{357}-\mathrm{SP}$ to $\mathrm{PMA}_{357}-\mathrm{SP}-\mathrm{PDMS}_{135}$ by polymer-polymer conjugation. (c) $\mathrm{PS}_{342}-\mathrm{SP}$ and $\mathrm{PS}_{342}-$ SP-PDMS ${ }_{135}$ by polymer-polymer conjugation. (d) PMMA $_{316}$-SP and PMMA $\mathrm{PM}_{316}-$ SP-PDMS $_{135}$ by polymer-polymer conjugation.

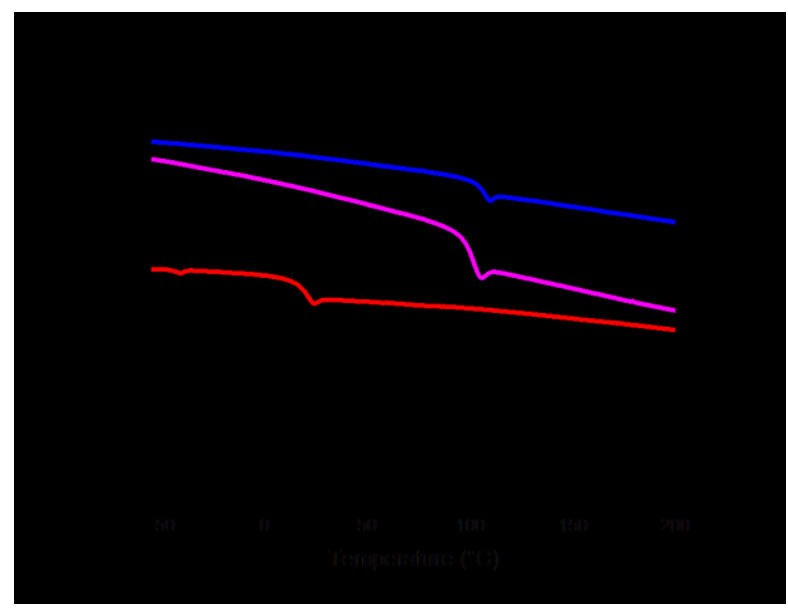

Fig. 5. DSC curves of block copolymers with a spiropyran at the junction of the blocks.

\section{Stimuli response of block copolymers with a spiropyran at the junction of blocks}

Spiropyran functionalized $A B$ block copolymers were exposed to ultra violet light. In response, they underwent a color change to violet as can be seen in (Fig. 6). 


\section{Before
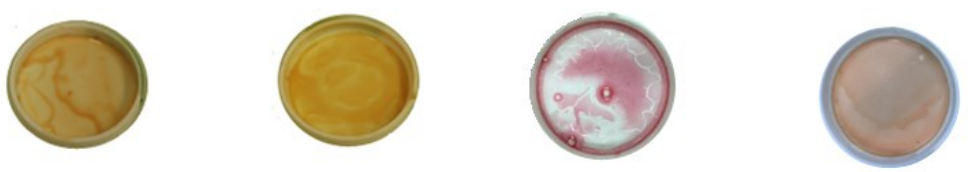 \\ After exposure
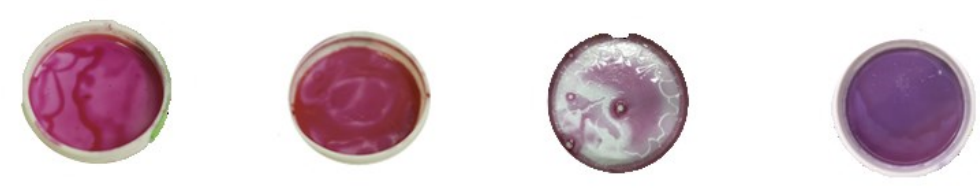 \\ PMA $_{357}$ SP-PLLA $_{81} \quad$ PMA $_{357}-$ SP-PDMS $_{135}$ PS $_{342}$-SP-PDMS $_{135}$ PMMA $_{316}-$ SP-PDMS $_{135}$}

Fig. 6 : Color change of block copolymers with a spiropyran at the junction of theblocks upon irradiation with UV light.

To characterize the color change, films of the block copolymers on quartz slides where irradiated with UV light and analyzed by UV-Vis spectroscopy. The spectra (Fig.7) show that the absorption band at in the vis region increases with irradiation time, which corresponds to the switching of the spiropyran into the merocyanine form. PMA-based block copolymers showed one absorption band with a maximum at $566 \mathrm{~nm}$ that corresponds to the non-aggregated merocyanine, similar to the homopolymer. In contrast to the PMMA-based homopolymer, $\mathrm{PS}_{342}-\mathrm{SP}-\mathrm{PDMS}_{135}$ only showed the absorption band of the non-aggregated merocyanine with its maximum at $570 \mathrm{~nm}$. Thus, for this block copolymer the presence of the PDMS block suppressed the aggregation of merocyanine moieties. The absorption of UV-irradiated PMMA PI6-SP-PDMS $_{134}$ has a maximum at $568 \mathrm{~nm}$, a strong shoulder at around $585 \mathrm{~nm}$ and a weak shoulder at $525 \mathrm{~nm}$. Thus, free merocyanine was accompanied by aggregates, whereby the amount of $\mathrm{J}$-aggregates is higher than the amount of $\mathrm{H}$-aggregates. This characteristic is similar to $\mathrm{PMMA}_{316}$-SP that was used as the precursor for the block copolymer. Plots of absorbance vs. time for all four block copolymers show that the absorbance increased with UV exposure time until it saturated between 30 and $35 \mathrm{~min}$ of exposure (Fig. $\mathbf{7 ( b )}$ and Fig. S3.4-Fig. 
S3.6).
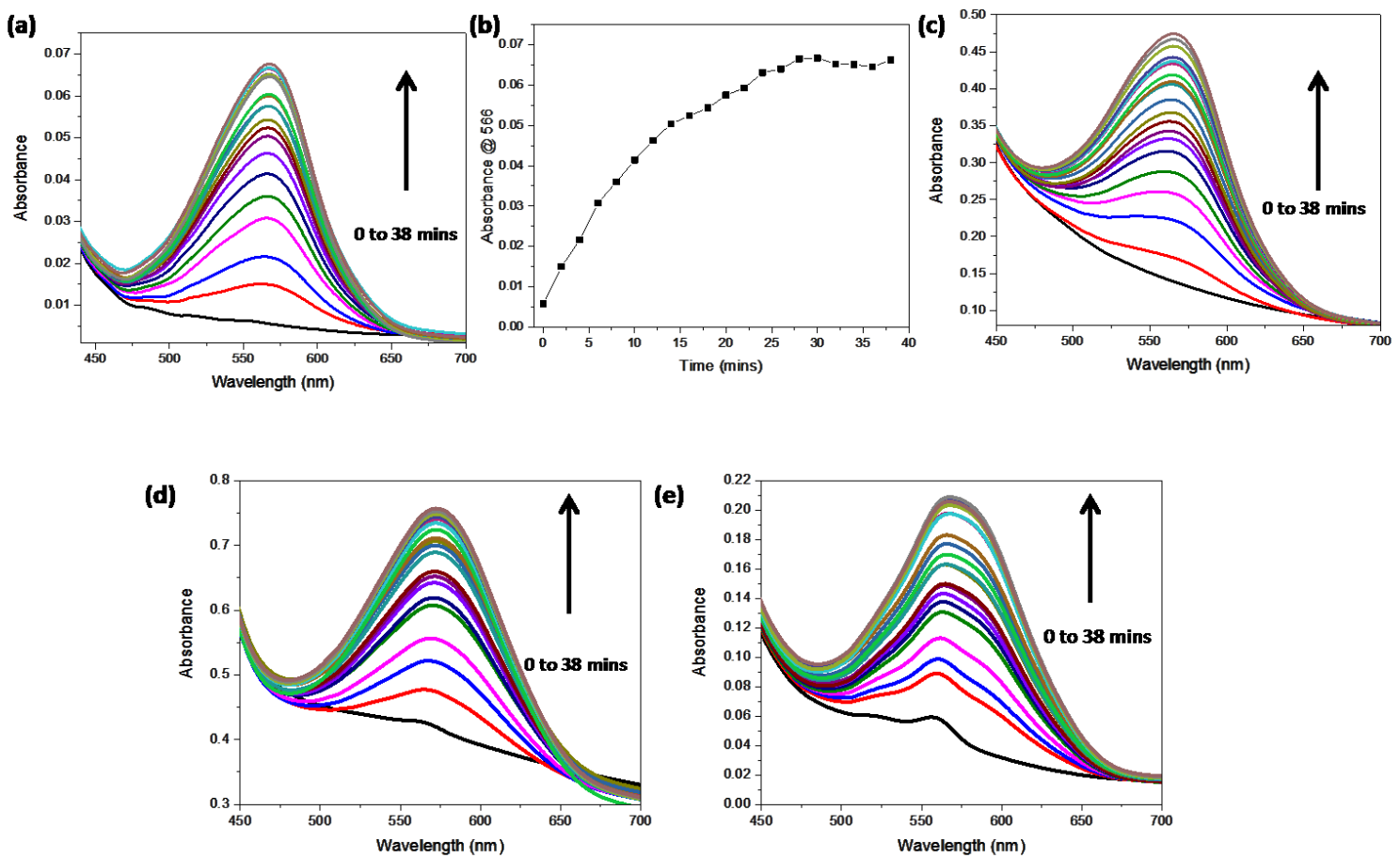

Fig. 7: UV-light response of block copolymers with a spiropyran at the junction of the blocks. (a) Vis-spectra of PMA $\mathrm{A}_{357}$-SPPLLA $_{81}$ upon irradiation with UV-light. (b) Change of absorbance with time for PMA P57-SP-PLLA $_{81}$ upon irradiation with UVlight. (c) Vis-spectra of PMA PM7-SP-PDMS $_{135}$ upon irradiation with UV-light. (d) Vis-spectra of PS S $_{342}$-SP-PDMS 135 upon irradiation with UV-light. (e) Vis-spectra of PMMA $_{316}$-SP-PDMS 135 upon irradiation with UV-light. Spectra were recorded every 2 min.

This process reverts unaided when the samples are left on the lab bench overnight. However, the reversion from merocyanine to the closed spiropyran form can be sped up by irradiation with white light such as the flash light from a smartphone. We exposed the slides of films of all four block copolymer samples to UV light for 40 min to convert the spiropyrans to the merocyanine form, and then moved them under direct white light from a smartphone flash light. The complete reversion of color in the films back to their original color was complete within 10 min (Fig. 6). By repeating this process, we could show that switching of spiropyrans could be achieved over multiple cycles (Fig. 6). The photo-response of the block copolymers proves that spiropyran is functional when incorporated at the junction of polymer blocks. 


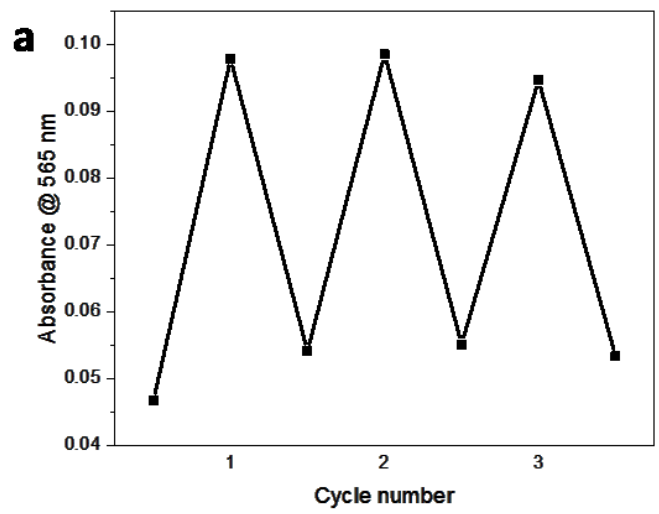

b
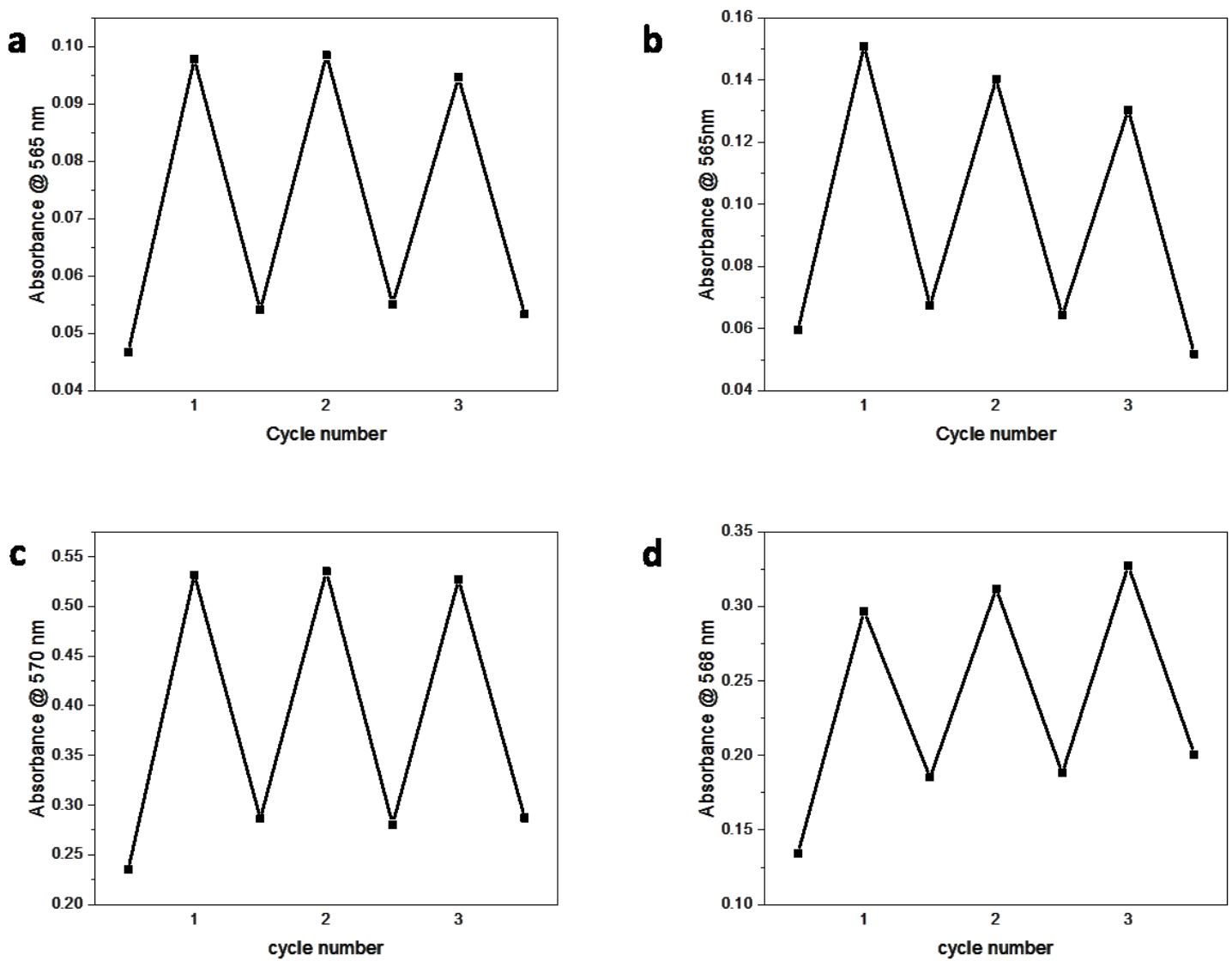

Fig. 8: Reversibility of the UV-light response of block copolymers with a spiropyran at the junction of the blocks. Absorbance at $\sim 570 \mathrm{~nm}$ of block copolymer films subjected to cycles of UV light exposure $(40 \mathrm{~min})$ and white light exposure (10 min) to switch spiropyran to merocyanine and back. (a) PMA $357-S P-P L L A_{81}$. (b) PMA PM7-SP-PDMS $_{135}$. (c) PS $342-S P-$ $\mathrm{PDMS}_{135}$. (d) $\mathrm{PMMA}_{316}-\mathrm{SP}-\mathrm{PDMS}_{135}$.

\section{Conclusions}

Spiropyrans are popular functional groups to render polymers responsive to light and other stimuli. However, synthesis routes towards block copolymers that possess a spiropyran between their blocks were unknown. We demonstrate routes to synthesize $A B$ block copolymers with a spiropyran moiety at the junction of blocks. The polymers reversibly switch color when irradiated by ultraviolet light and visible light over multiple cycles, demonstrating that the spiropyrans are functional in the bulk. Moreover, the architecture of the polymers can reduce the propensity of the merocyanine to aggregate. The block copolymers could be used to investigate the effect of phase separation on the mechanochromic response of spiropyrans. As the spiropyran changes between an unpolar to a polar zwitterionic species at the interface of the two phases, block copolymers with a spiropyran at the block junction may be useful to switch morphologies of self-assembled structures, e.g. by enhancing phase separation on demand. The zwitterionic group could also be used to reversibly adhere block copolymers to surfaces, and could be used to control the flux of solutes through a polymer layer. Therefore, these block copolymers could be useful building blocks for the preparation of bioinspired and biomimetic nanostructures, such as polymersomes and block copolymer membranes with switchable permeability. 


\section{Acknowledgements}

This work was supported by the Swiss National Science Foundation through the National Center of Competence in Research (NCCR) Bio-Inspired Materials and the projects PP00P2_144697 and PP00P2_172927.

\section{Declaration of interest}

None

\section{Data Availability Statement}

The datasets generated and analyzed during the current study will be made available in the Zenodo repository during the production of this article and before its publication.

\section{References}

[1] M.M. Caruso, D.A. Davis, Q. Shen, S.A. Odom, N.R. Sottos, S.R. White, J.S. Moore, Mechanicallyinduced chemical changes in polymeric materials, Chem. Rev. (Washington, DC, U. S.) 109 (2009) 5755-5798. https://doi.org/10.1021/cr9001353.

[2] F. Ciardelli, G. Ruggeri, A. Pucci, Dye-containing polymers: methods for preparation of mechanochromic materials, Chem. Soc. Rev. 42 (2013) 857-870.

https://doi.org/10.1039/C2CS35414D.

[3] T. Manouras, M. Vamvakaki, Field responsive materials: photo-, electro-, magnetic- and ultrasound-sensitive polymers, Polym. Chem. 8 (2017) 74-96. https://doi.org/10.1039/C6PY01455K. [4] M. Wei, Y. Gao, X. Li, M.J. Serpe, Stimuli-responsive polymers and their applications, Polym. Chem. 8 (2017) 127-143. https://doi.org/10.1039/C6PY01585A.

[5] J. Hu, H. Meng, G. Li, S.I. Ibekwe, A review of stimuli-responsive polymers for smart textile applications, Smart Materials and Structures 21 (2012) 053001. https://doi.org/10.1088/09641726/21/5/053001.

[6] R. Merindol, A. Walther, Materials learning from life: concepts for active, adaptive and autonomous molecular systems, Chem. Soc. Rev. 46 (2017) 5588-5619.

https://doi.org/10.1039/C6CS00738D.

[7] M.A.C. Stuart, W.T.S. Huck, J. Genzer, M. Müller, C. Ober, M. Stamm, G.B. Sukhorukov, I. Szleifer, V.V. Tsukruk, M. Urban, F. Winnik, S. Zauscher, I. Luzinov, S. Minko, Emerging applications of stimuliresponsive polymer materials, Nat. Mater. 9 (2010) 101. https://doi.org/10.1038/nmat2614.

[8] E. Cabane, X. Zhang, K. Langowska, C.G. Palivan, W. Meier, Stimuli-Responsive Polymers and Their Applications in Nanomedicine, Biointerphases 7 (2012) 9. https://doi.org/10.1007/s13758-011-0009$\underline{3}$.

[9] F.H. Schacher, P.A. Rupar, I. Manners, Functional Block Copolymers: Nanostructured Materials with Emerging Applications, Angew. Chem., Int. Ed. 51 (2012) 7898-7921.

https://doi.org/doi:10.1002/anie.201200310.

[10] K. Renggli, P. Baumann, K. Langowska, O. Onaca, N. Bruns, W. Meier, Selective and Responsive Nanoreactors, Adv. Funct. Mater. 21 (2011) 1241-1259. https://doi.org/10.1002/adfm.201001563.

[11] C.G. Palivan, R. Goers, A. Najer, X. Zhang, A. Car, W. Meier, Bioinspired polymer vesicles and membranes for biological and medical applications, Chem. Soc. Rev. 45 (2016) 377-411.

https://doi.org/10.1039/C5CS00569H.

[12] J. Gaitzsch, X. Huang, B. Voit, Engineering Functional Polymer Capsules toward Smart Nanoreactors, Chem. Rev. (Washington, DC, U. S.) 116 (2016) 1053-1093.

https://doi.org/10.1021/acs.chemrev.5b00241.

[13] J.-F. Gohy, Y. Zhao, Photo-responsive block copolymer micelles: design and behavior, Chem. Soc. Rev. 42 (2013) 7117-7129. https://doi.org/10.1039/C3CS35469E. 
[14] T. Rudolph, F.H. Schacher, Selective crosslinking or addressing of individual domains within block copolymer nanostructures, Eur. Polym. J. 80 (2016) 317-331.

https://doi.org/https://doi.org/10.1016/i.eurpolymj.2016.03.018.

[15] O. Grimm, F. Wendler, F.H. Schacher, Micellization of Photo-Responsive Block Copolymers, Polymers 9 (2017) 396. https://doi.org/10.3390/polym9090396.

[16] X. Yuan, K. Fischer, W. Schärtl, Photocleavable Microcapsules Built from Photoreactive Nanospheres, Langmuir 21 (2005) 9374-9380. https://doi.org/10.1021/la051491+.

[17] H. Zhao, E.S. Sterner, E.B. Coughlin, P. Theato, o-Nitrobenzyl Alcohol Derivatives: Opportunities in Polymer and Materials Science, Macromolecules 45 (2012) 1723-1736.

https://doi.org/10.1021/ma201924h.

[18] W. Zhu, L. Zhang, Y. Chen, K. Zhang, A UV-Cleavable Bottlebrush Polymer with o-NitrobenzylLinked Side Chains, Macromol. Rapid Commun. 38 (2017) 1700007.

https://doi.org/doi:10.1002/marc.201700007.

[19] C. Tonhauser, A.A. Golriz, C. Moers, R. Klein, H.-J. Butt, H. Frey, Stimuli-Responsive Y-Shaped Polymer Brushes Based on Junction-Point-Reactive Block Copolymers, Adv. Mater. (Weinheim, Ger.) 24 (2012) 5559-5563. https://doi.org/10.1002/adma.201202105.

[20] C.-g. Mu, X.-d. Fan, W. Tian, Y. Bai, Z. Yang, W.-w. Fan, H. Chen, Synthesis and stimulusresponsive micellization of a well-defined H-shaped terpolymer, Polym. Chem. 3 (2012) 3330-3339. https://doi.org/10.1039/C2PY20586F.

[21] T. Rudolph, M.J. Barthel, F. Kretschmer, U. Mansfeld, S. Hoeppener, M.D. Hager, U.S. Schubert, F.H. Schacher, Poly(2-vinyl pyridine)-block-Poly(ethylene oxide) Featuring a Furan Group at the Block Junction-Synthesis and Functionalization, Macromol. Rapid Commun. 35 (2014) 916-921. https://doi.org/10.1002/marc.201300875.

[22] J. Tian, C. Xiao, B. Huang, X. Jiang, H. Cao, F. Liu, W. Zhang, Combating Multidrug Resistance through an NIR-Triggered Cyanine-Containing Amphiphilic Block Copolymer, ACS Applied Bio Materials (2019). https://doi.org/10.1021/acsabm.8b00793.

[23] Y. Luo, D. Montarnal, N.J. Treat, P.D. Hustad, M.D. Christianson, E.J. Kramer, G.H. Fredrickson, C.J. Hawker, Enhanced Block Copolymer Phase Separation Using Click Chemistry and Ionic Junctions, ACS Macro Lett. 4 (2015) 1332-1336. https://doi.org/10.1021/acsmacrolett.5b00767.

[24] E. Ji, V. Pellerin, L. Rubatat, E. Grelet, A. Bousquet, L. Billon, Self-Assembly of Ionizable "Clicked" P3HT-b-PMMA Copolymers: Ionic Bonding Group/Counterion Effects on Morphology,

Macromolecules 50 (2017) 235-243. https://doi.org/10.1021/acs.macromol.6b02101.

[25] S. Woo, S. Jo, D.Y. Ryu, S.-H. Choi, Y. Choe, A. Khan, J. Huh, J. Bang, Molecular Tailoring of

Poly(styrene-b-methyl methacrylate) Block Copolymer Toward Perpendicularly Oriented

Nanodomains with Sub-10 nm Features, ACS Macro Lett. 6 (2017) 1386-1391.

https://doi.org/10.1021/acsmacrolett.7b00856.

[26] K.S. Lee, J. Lee, J. Kwak, H.C. Moon, J.K. Kim, Reduction of Line Edge Roughness of Polystyreneblock-Poly(methyl methacrylate) Copolymer Nanopatterns By Introducing Hydrogen Bonding at the Junction Point of Two Block Chains, ACS Appl. Mater. Interfaces 9 (2017) 31245-31251.

https://doi.org/10.1021/acsami.6b15885.

[27] B. Kerscher, T.M. Trötschler, B. Pásztói, S. Gröer, Á. Szabó, B. Iván, R. Mülhaupt, Thermoresponsive Polymer lonic Liquids and Nanostructured Hydrogels Based upon Amphiphilic Polyisobutylene-b-poly(2-ethyl-2-oxazoline) Diblock Copolymers, Macromolecules 52 (2019) 33063318. https://doi.org/10.1021/acs.macromol.9b00296.

[28] S.L. Potisek, D.A. Davis, N.R. Sottos, S.R. White, J.S. Moore, Mechanophore-Linked Addition Polymers, J. Am. Chem. Soc. 129 (2007) 13808-13809. https://doi.org/10.1021/ja076189x.

[29] D.A. Davis, A. Hamilton, J. Yang, L.D. Cremar, D. Van Gough, S.L. Potisek, M.T. Ong, P.V. Braun, T.J. Martínez, S.R. White, J.S. Moore, N.R. Sottos, Force-induced activation of covalent bonds in mechanoresponsive polymeric materials, Nature 459 (2009) 68-72.

https://doi.org/10.1038/nature07970. 
[30] G. O'Bryan, B.M. Wong, J.R. McElhanon, Stress Sensing in Polycaprolactone Films via an Embedded Photochromic Compound, ACS Appl. Mater. Interfaces 2 (2010) 1594-1600.

https://doi.org/10.1021/am100050v.

[31] G.R. Gossweiler, G.B. Hewage, G. Soriano, Q. Wang, G.W. Welshofer, X. Zhao, S.L. Craig, Mechanochemical Activation of Covalent Bonds in Polymers with Full and Repeatable Macroscopic Shape Recovery, ACS Macro Lett. 3 (2014) 216-219. https://doi.org/10.1021/mz500031q.

[32] X. Wang, J. Hu, G. Liu, J. Tian, H. Wang, M. Gong, S. Liu, Reversibly switching bilayer permeability and release modules of photochromic polymersomes stabilized by cooperative noncovalent interactions, J. Am. Ceram. Soc. 137 (2015) 15262-15275. https://doi.org/10.1021/jacs.5b10127.

[33] R. Klajn, Spiropyran-based dynamic materials, Chem. Soc. Rev. 43 (2014) 148-184. https://doi.org/10.1039/C3CS60181A.

[34] Y. Hirshberg, E. Fischer, Photochromism and reversible multiple internal transitions in some spiropyrans at low temperatures. Part I, J. Chem. Soc. (1954) 297-303.

https://doi.org/10.1039/JR9540000297.

[35] N. Kobayashi, S. Sato, K. Takazawa, K. Ikeda, R. Hirohashi, A new polymer electrolyte for reversible photoresponsive ionic conduction, Electrochim. Acta 40 (1995) 2309-2311. https://doi.org/https://doi.org/10.1016/0013-4686(95)00184-G.

[36] X. Guo, D. Zhang, G. Yu, M. Wan, J. Li, Y. Liu, D. Zhu, Reversible Photoregulation of the Electrical Conductivity of Spiropyran-Doped Polyaniline for Information Recording and Nondestructive Processing, Adv. Mater. (Weinheim, Ger.) 16 (2004) 636-640.

https://doi.org/doi:10.1002/adma.200305792.

[37] Y. Bardavid, I. Goykhman, D. Nozaki, G. Cuniberti, S. Yitzchaik, Dipole Assisted Photogated Switch in Spiropyran Grafted Polyaniline Nanowires, J. Phys. Chem. C 115 (2011) 3123-3128.

https://doi.org/10.1021/jp110665j.

[38] Y.S. Park, Y. Ito, Y. Imanishi, Photocontrolled Gating by Polymer Brushes Grafted on Porous Glass Filter, Macromolecules 31 (1998) 2606-2610. https://doi.org/10.1021/ma9605199.

[39] D. Dattilo, L. Armelao, G. Fois, G. Mistura, M. Maggini, Wetting Properties of Flat and Porous Silicon Surfaces Coated with a Spiropyran, Langmuir 23 (2007) 12945-12950.

https://doi.org/10.1021/la7024878.

[40] S.H. Anastasiadis, M.I. Lygeraki, A. Athanassiou, M. Farsari, D. Pisignano, Reversibly PhotoResponsive Polymer Surfaces for Controlled Wettability, J. Adhes. Sci. Technol. 22 (2008) 1853-1868. https://doi.org/10.1163/156856108X320014.

[41] K. Keiichi, M. Nakamura, H. Sakamoto, R.M. Uda, M. Sumida, M. Yokoyama, Cation

Complexation, Photochromism, and Aggregation of Copolymers Carrying Crown Ether and

Spirobenzopyran Moieties at the Side Chains, Bull. Chem. Soc. Jpn. 76 (2003) 209-215.

https://doi.org/10.1246/bcsj.76.209.

[42] F. Benito-Lopez, S. Scarmagnani, Z. Walsh, B. Paull, M. Macka, D. Diamond, Spiropyran modified micro-fluidic chip channels as photonically controlled self-indicating system for metal ion accumulation and release, Sens. Actuators, B 140 (2009) 295-303.

https://doi.org/https://doi.org/10.1016/i.snb.2009.03.080.

[43] K.H. Fries, J.D. Driskell, S. Samanta, J. Locklin, Spectroscopic Analysis of Metal lon Binding in Spiropyran Containing Copolymer Thin Films, Anal. Chem. 82 (2010) 3306-3314.

https://doi.org/10.1021/ac1001004.

[44] A. Higuchi, A. Hamamura, Y. Shindo, H. Kitamura, B.O. Yoon, T. Mori, T. Uyama, A. Umezawa, Photon-Modulated Changes of Cell Attachments on Poly(spiropyran-co-methyl methacrylate)

Membranes, Biomacromolecules 5 (2004) 1770-1774. https://doi.org/10.1021/bm049737x.

[45] D.-J. Chung, Y. Ito, Y. Imanishi, Preparation of porous membranes grafted with poly(spiropyrancontaining methacrylate) and photocontrol of permeability, J. Appl. Polym. Sci. 51 (1994) 2027-2033. https://doi.org/doi:10.1002/app.1994.070511207.

[46] K. Schöller, S. Küpfer, L. Baumann, P.M. Hoyer, D. de Courten, R.M. Rossi, A. Vetushka, M. Wolf, N. Bruns, L.J. Scherer, From Membrane to Skin: Aqueous Permeation Control Through Light- 
Responsive Amphiphilic Polymer Co-Networks, Adv. Funct. Mater. 24 (2014) 5194-5201. https://doi.org/doi:10.1002/adfm.201400671.

[47] D.S. Achilleos, M. Vamvakaki, Multiresponsive Spiropyran-Based Copolymers Synthesized by Atom Transfer Radical Polymerization, Macromolecules 43 (2010) 7073-7081.

https://doi.org/10.1021/ma101331u.

[48] L. Hauser, A.-C. Knall, M. Roth, G. Trimmel, M. Edler, T. Griesser, W. Kern, Reversible photochromism of polynorbornenes bearing spiropyran side groups, Monatsh. Chem. 143 (2012) 1551-1558. https://doi.org/10.1007/s00706-012-0827-0.

[49] T. Renkecz, G. Mistlberger, M. Pawlak, V. Horváth, E. Bakker, Molecularly Imprinted Polymer Microspheres Containing Photoswitchable Spiropyran-Based Binding Sites, ACS Appl. Mater. Interfaces 5 (2013) 8537-8545. https://doi.org/10.1021/am401958e.

[50] N. Murase, T. Mukawa, H. Sunayama, T. Takeuchi, Molecularly imprinted polymers bearing spiropyran-based photoresponsive binding sites capable of photo-triggered switching for molecular recognition activity, J. Polym. Sci., Part B: Polym. Phys. 54 (2016) 1637-1644.

https://doi.org/doi:10.1002/polb.24066.

[51] F. Krohm, J. Kind, R. Savka, M. Alcaraz Janßen, D. Herold, H. Plenio, C.M. Thiele, A. AndrieuBrunsen, Photochromic spiropyran- and spirooxazine-homopolymers in mesoporous thin films by surface initiated ROMP, J. Mater. Chem. C 4 (2016) 4067-4076. https://doi.org/10.1039/C5TC04054J. [52] C. Ventura, P. Thornton, S. Giordani, A. Heise, Synthesis and photochemical properties of spiropyran graft and star polymers obtained by 'click' chemistry, Polym. Chem. 5 (2014) 6318-6324. https://doi.org/10.1039/C4PY00778F.

[53] C.P. Anja, S. Katrin, B. Lukas, M.R. René, D. Kathrin, Z. Ulrich, C. Damien de, W. Martin, F.B. Luciano, J.S. Lukas, ATRP-based synthesis and characterization of light-responsive coatings for transdermal delivery systems, Science and Technology of Advanced Materials 16 (2015) 034604.

[54] F. Jiang, S. Chen, Z. Cao, G. Wang, A photo, temperature, and pH responsive spiropyranfunctionalized polymer: Synthesis, self-assembly and controlled release, Polymer 83 (2016) 85-91. https://doi.org/https://doi.org/10.1016/i.polymer.2015.12.027.

[55] G.I. Peterson, M.B. Larsen, M.A. Ganter, D.W. Storti, A.J. Boydston, 3D-Printed Mechanochromic Materials, ACS Appl. Mater. Interfaces 7 (2015) 577-583. https://doi.org/10.1021/am506745m.

[56] M. Li, Q. Zhang, S. Zhu, Photo-inactive divinyl spiropyran mechanophore cross-linker for realtime stress sensing, Polymer 99 (2016) 521-528.

https://doi.org/https://doi.org/10.1016/i.polymer.2016.07.057.

[57] S. Jiang, L. Zhang, T. Xie, Y. Lin, H. Zhang, Y. Xu, W. Weng, L. Dai, Mechanoresponsive PS-PnBA-PS Triblock Copolymers via Covalently Embedding Mechanophore, ACS Macro Lett. 2 (2013) 705-709. https://doi.org/10.1021/mz400198n.

[58] L.-J. Wang, X.-J. Zhou, X.-H. Zhang, B.-Y. Du, Enhanced Mechanophore Activation within Micelles, Macromolecules 49 (2016) 98-104. https://doi.org/10.1021/acs.macromol.5b02383.

[59] M. Sommer, H. Komber, Spiropyran Main-Chain Conjugated Polymers, Macromol. Rapid Commun. 34 (2013) 57-62. https://doi.org/doi:10.1002/marc.201200688.

[60] M.R.J. Scherer, L. Li, P.M.S. Cunha, O.A. Scherman, U. Steiner, Enhanced Electrochromism in Gyroid-Structured Vanadium Pentoxide, Adv. Mater. (Weinheim, Ger.) 24 (2012) 1217-1221. https://doi.org/doi:10.1002/adma.201104272.

[61] C. Beyer, H.-A. Wagenknecht, Synthesis of Spiropyrans As Building Blocks for Molecular Switches and Dyads, J. Org. Chem. 75 (2010) 2752-2755. https://doi.org/10.1021/jo100309r.

[62] T.P. Vales, I.W.T. Badon, H.-J. Kim, Multi-Responsive Hydrogels Functionalized with a Photochromic Spiropyran-Conjugated Chitosan Network, Macromol. Res. (2018).

https://doi.org/10.1007/s13233-018-6126-9.

[63] E. Goldburt, F. Shvartsman, S. Fishman, V. Krongauz, Intramolecular interactions in photochromic spiropyran-merocyanine polymers, Macromolecules 17 (1984) 1225-1230.

https://doi.org/10.1021/ma00136a020. 
[64] H. Tomioka, T. Itoh, Photochromism of spiropyrans in organized molecular assemblies.

Formation of J- and $\mathrm{H}$-aggregates of photomerocyanines in bilayers-clay matrices, J. Chem. Soc., Chem. Commun. (1991) 532-533. https://doi.org/10.1039/C39910000532.

[65] Y. Wu, C. Zhang, X. Qu, Z. Liu, Z. Yang, Light-Triggered Reversible Phase Transfer of Composite Colloids, Langmuir 26 (2010) 9442-9448. https://doi.org/10.1021/la100458j.

[66] E. Goldburt, F. Shvartsman, V. Krongauz, "Zipper" crystallization of polymers with spiropyran side groups, Macromolecules 17 (1984) 1876-1878. https://doi.org/10.1021/ma00139a044.

[67] R. Fu, G.-D. Fu, Polymeric nanomaterials from combined click chemistry and controlled radical polymerization, Polym. Chem. 2 (2011) 465-475. https://doi.org/10.1039/COPY00174K.

[68] H. Erothu, A.A. Sohdi, A.C. Kumar, A.J. Sutherland, C. Dagron-Lartigau, A. Allal, R.C. Hiorns, P.D. Topham, Facile synthesis of poly(3-hexylthiophene)-block-poly(ethylene oxide) copolymers via Steglich esterification, Polym. Chem. 4 (2013) 3652-3655. https://doi.org/10.1039/C3PY00505D.

[69] W.-W. Wang, L. Jiang, W.-Y. Ren, C.-M. Zhang, C.-Z. Man, T.-P. Nguyen, Y. Dan, The crystallinity, thermal properties and microscopic morphology of di-block copolymers of l-lactide and several acrylates, RSC Adv. 6 (2016) 31934-31946. https://doi.org/10.1039/C5RA24327K.

[70] R.-C. Zhang, D. Sun, A. Lu, M. Zhong, G. Xiong, Y. Wan, Equilibrium Melting Temperature of Polymorphic Poly(I-lactide) and Its Supercooling Dependence on Growth Kinetics, Polymers 9 (2017) 625. https://doi.org/10.3390/polym9110625.

[71] R.H. Wiley, G.M. Brauer, Refractometric determination of second-order transition temperatures in polymers. III. Acrylates and methacrylates, J. Polym. Sci. 3 (1948) 647-651.

https://doi.org/10.1002/pol.1948.120030506.

[72] R.F. Boyer, Styrene polymers. Physical properties-glass transition, in: H.F. Mark (Ed.), Encyclopedia of Polymer Science and Technology, Interscience Publishers New York, 1970, pp. 309326.

[73] J.A. Johnson, D.W. Jones, The mechanical properties of PMMA and its copolymers with ethyl methacrylate and butyl methacrylate, J. Mater. Sci. 29 (1994) 870-876.

https://doi.org/10.1007/bf00351404. 